OESOPHAGUS

\title{
Increasing incidence of Barrett's oesophagus in the general population
}

\author{
E M van Soest, J P Dieleman, P D Siersema, M C J M Sturkenboom, E J Kuipers

See end of article for authors' affiliations

.....................

Correspondence to: Mrs E M van Soest Department of Gastroenterology and Hepatology, Erasmus University Medical Centre, Postbus 2040, 3000 CA Rotterdam, the Netherlands; e.vansoest@ erasmusmc.n

Revised version received 16 March 2005 Accepted for publication 12 April 2005 Published online first 27 April 2005
Background: Barrett's oesophagus (BO) predisposes to oesophageal adenocarcinoma. Epidemiological data suggest that the incidence of $\mathrm{BO}$ is rising but it is unclear whether this reflects a true rise in incidence of $\mathrm{BO}$ or an increase in detection secondary to more upper gastrointestinal endoscopies performed. This study aimed to examine the changes in $\mathrm{BO}$ incidence relative to the number of upper gastrointestinal endoscopies performed in the general population.

Methods: We conducted a cohort study using the Integrated Primary Care Information database. This general practice research database contains the complete and longitudinal electronic medical records of more than 500000 persons.

Results: In total, 260 incident cases of $\mathrm{BO}$ were identified during the study period. The incidence of $\mathrm{BO}$ increased from 14.3/100 000 person years in 1997 (95\% confidence interval (CI) 8.6-22.4) to 23.1/ 100000 person years (95\% Cl 17.2-30.6) in $2002\left(r^{2}=0.87\right)$. The number of upper gastrointestinal endoscopies decreased from $7.2 / 1000$ person years $(95 \% \mathrm{Cl} 6.7-7.7)$ to $5.7 / 1000$ person years $(95 \% \mathrm{Cl}$ 5.4-6.1) over the same time period. This resulted in an overall increase in detected BO per 1000 endoscopies from 19.8 (95\% Cl 12.0-31.0) in 1997 to 40.5 (95\% Cl 30.0-53.5) in $2002\left(r^{2}=0.93\right)$. The incidence of adenocarcinoma increased from $1.7 / 100000$ person years $(95 \% \mathrm{Cl} 0.3-5.4)$ in 1997 to $6.0 / 100000$ person years $(95 \% \mathrm{Cl} 3.3-10.2)$ in $2002\left(r^{2}=0.87\right)$.

Conclusion: The incidence of diagnosed $\mathrm{BO}$ is increasing, independent of the number of upper gastrointestinal endoscopies that are being performed. This increase in BO incidence will likely result in a further increase in the incidence of oesophageal adenocarcinomas in the near future.
$\mathrm{T}$ he incidence of adenocarcinoma of the oesophagus (AC) has increased dramatically since the 1970s, at a rate faster than any other type of cancer. ${ }^{1-3}$ Since the 1980s the incidence has been rising by $4-10 \%$ annually, and presently this increasing trend is still continuing. ${ }^{45}$ The cause of the ongoing increase is unknown. Suggested explanations include an increase in the prevalence of risk factors such as smoking and obesity, and a decrease in the prevalence of Helicobacter pylori infection..$^{6-8}$ However, the most recognised risk factor for AC is Barrett's oesophagus (BO).

$\mathrm{BO}$ is a condition in which the squamous epithelium of the oesophagus is replaced by columnar lined epithelium, containing specialised intestinal metaplasia with the presence of goblet cells. ${ }^{9}$ This replacement is probably a consequence of prolonged reflux of gastric contents into the lower oesophagus. It is estimated that $\mathrm{BO}$ increases the risk of AC by approximately 30-125-fold. ${ }^{10}{ }^{11}$

As most, if not all, ACs of the oesophagus are preceded by $\mathrm{BO},{ }^{12}$ it is suspected that the increase in incidence of $\mathrm{AC}$ is caused by an increase in the incidence of BO. However, epidemiological data on the incidence of $\mathrm{BO}$ in the general population are scarce and conflicting. An increase in the incidence of $\mathrm{BO}$ has been reported but it is unclear whether this reflects a true rise in occurrence or an increase in the diagnosis of $\mathrm{BO}$ because of more upper gastrointestinal endoscopies being performed and/or increased alertness..$^{13} 14$

This study aimed to investigate the changes in incidence of diagnosed $\mathrm{BO}$ in relation to the number of upper gastrointestinal endoscopies, using a unique population based general practice research database containing detailed medical data on more than half a million patients.

\section{METHODS \\ Setting}

The Integrated Primary Care Information (IPCI) database is a general practitioner research database, presently containing more than 500000 computer based patient records, obtained from and maintained by 151 general practitioners in the Netherlands. This dynamic database was started in 1992 and has expanded since. The IPCI population has the same sex and age distribution as the Dutch population. The database is maintained by the Department of Medical Informatics of the Erasmus MC, University Medical Centre, Rotterdam, the Netherlands.

In the Dutch health care system, almost all citizens are registered with a general practitioner practice and a general practitioner acts as a gatekeeper to, and as a central receiver of information from, secondary care. The medical records from each individual patient can therefore be assumed to contain all relevant medical information about that person.

The electronic records of the IPCI database contain anonymous demographic information as well as information about symptoms and diagnoses (using the International Classification for Primary Care (ICPC) $)^{15}$ and free text), drug prescriptions with ICPC coded indications and dosage regimens, referrals to secondary care, laboratory values, measurements such as blood pressure and cholesterol levels, and hospitalisations. Summaries of hospital discharge letters or information from specialists are included as free text and

Abbreviations: $B O$, Barrett's oesophagus; $A C$, adenocarcinoma; IPCI, Integrated Primary Care Information; ICPC, International Classification for Primary Care 
copies can be provided on request. In order to ensure completeness of the data, participating general practitioners are not allowed to use additional paper based medical records.

The IPCI database complies with European Union guidelines on the use of medical data for medical research and has been proven valid for pharmacoepidemiological research. Extended details on the database have been described elsewhere. ${ }^{16}$ The Scientific and Ethical Advisory Board of the IPCI project approved the study.

\section{Study population}

We included all patients contributing data to the database between January 1996 and December 2003. One year of database history was required to be able to describe the patient's medical history, and discriminate between prevalent and incident cases of BO. Follow up started on 1 January 1996 or on the date that one year of valid history was available, whichever was latest. Follow up ended on the date of transferring out of the general practitioner practice, last data obtained from the general practitioner, death of the patient, occurrence of the specific study outcome (BO or AC), or 31 December 2003, whichever came first.

\section{Identification and validation of Barrett's oesophagus} The ICPC does not include a diagnosis code for BO. Therefore, we applied a sensitive search algorithm to the free text of each electronic medical record using the Dutch version of the words "Barrett", "intestinal metaplasia", and "columnar epithelium" (including obvious misspellings and abbreviations). Each patient record containing one or more of these words was reviewed manually by the primary researcher (ES) and a gastroenterologist (PS) to confirm or reject a diagnosis of BO. Cases were considered as definite if the record stated that the patient had $\mathrm{BO}$ and contained results from oesophageal biopsies in which intestinal metaplasia was confirmed. Patients were defined as possible cases if the record stated that the patient had $\mathrm{BO}$ and contained additional information making this diagnosis likely, such as notifications of performed surveillance endoscopies or length of the BO segment, but no pathological report was entered. For possible cases, specialist letters including pathological reports were requested from the general practitioners.

All records of $\mathrm{BO}$ patients were reviewed to assess the date of first diagnosis of BO. Cases were considered as incident cases if the date of diagnosis fell after inclusion of the patient in the study cohort. Patients with a diagnosis of BO prior to study entry were classified as prevalent $\mathrm{BO}$ cases and were not evaluated further.

\section{Upper gastrointestinal endoscopies}

In order to identify upper gastrointestinal endoscopies, we performed an extended computerised database search within the free text of the medical records using the Dutch version of the word "scopy" and combinations of words used in the records to indicate referrals for endoscopy, gastroenterologists, and gastrointestinal diagnoses. We automatically removed negations.

Upper gastrointestinal endoscopies were electronically categorised as valid if the record included information retrieved from specialist letters containing diagnoses that can only be confirmed by upper gastrointestinal endoscopy. Records with possible upper gastrointestinal endoscopies were reviewed manually and classified as valid or not valid.

We did not count referrals for upper gastrointestinal endoscopy if they did not have a subsequent recording of results or a change in medication for an upper gastrointestinal tract disorder within a few months after referral. This was based on the experience that a substantial proportion of patients with a referral for gastrointestinal endoscopy do not show up because of fear or because of disappearance of symptoms. Upper gastrointestinal endoscopies performed after the date of diagnosis of $\mathrm{BO}$ or oesophageal AC were not taken into account, thereby excluding surveillance and control endoscopies for BO or AC. To prevent overestimation of the number of upper gastrointestinal endoscopies at which BO could be detected (for example, in the case where several endoscopies were performed during one hospitalisation for upper gastrointestinal problems), we excluded upper gastrointestinal endoscopies performed within three months of the previous one.

\section{Identification and validation of oesophageal adenocarcinoma}

We included all patients with ICPC codes D77.1 (malignant neoplasia of the oesophagus) and D77.0 (malignant neoplasia of the tractus digestivus-not specified) for further evaluation. In addition, we applied a search algorithm to the free text of each electric medical record using combinations of the Dutch versions of the words oesophagus, cancer, carcinoma, malignancy, and neoplasia. All obtained records were reviewed manually for the presence of carcinoma in the oesophagus, type of carcinoma (squamous cell, adeno, or other carcinoma) and date of diagnosis. Cases

Table 1 Incidence of Barrett's oesophagus (BO) by calendar year, sex, and age category*

\begin{tabular}{|c|c|c|c|c|c|}
\hline & $\begin{array}{l}\text { No of BO } \\
\text { cases }\end{array}$ & $\begin{array}{l}\text { No of } \\
\text { person years }\end{array}$ & $\begin{array}{l}\text { No of upper GI } \\
\text { endoscopies }\end{array}$ & $\begin{array}{l}\text { BO/ } 100000 \\
\text { person years } \\
(95 \% \mathrm{Cl})\end{array}$ & $\begin{array}{l}\text { BO/ } 1000 \text { upper } \\
\text { GI endoscopies } \\
(95 \% \mathrm{CI})\end{array}$ \\
\hline Overall & 260 & 1314933 & 8495 & $19.8(17.5-22.3)$ & $30.6(27.1-34.5)$ \\
\hline 1996 & 7 & 64972 & 421 & $10.8(4.8-21.2)$ & $16.6(7.4-32.6)$ \\
\hline 1997 & 17 & 118953 & 858 & $14.3(8.6-22.4)$ & $19.8(12.0-31.0)$ \\
\hline 1998 & 27 & 162271 & 1148 & $16.6(11.2-23.8)$ & $23.5(15.8-33.7)$ \\
\hline 1999 & 45 & 218630 & 1483 & $20.6(15.2-27.3)$ & $30.3(22.4-40.2)$ \\
\hline 2000 & 43 & 224570 & 1384 & $19.2(14.1-25.5)$ & $31.1(22.8-41.4)$ \\
\hline 2001 & 48 & 207932 & 1338 & $23.1(17.2-30.3)$ & $35.9(26.8-47.1)$ \\
\hline 2002 & 46 & 198754 & 1136 & $23.1(17.2-30.6)$ & $40.5(30.0-53.5)$ \\
\hline 2003 & 27 & 118853 & 727 & $22.7(15.3-32.6)$ & $37.1(25.0-53.2)$ \\
\hline \multicolumn{6}{|l|}{ Sex } \\
\hline Men & 158 & 652310 & 3952 & $24.2(20.7-28.2)$ & $40.0(34.1-46.6)$ \\
\hline Women & 102 & 662623 & 4543 & $15.4(12.6-18.6)$ & $22.5(18.4-27.1)$ \\
\hline \multicolumn{6}{|c|}{ Age at diagnosis (y) } \\
\hline$<40$ & 17 & 717690 & 1858 & $2.4(1.4-3.7)$ & $9.2(5.5-14.3)$ \\
\hline $40-60$ & 104 & 383016 & 3487 & $27.2(22.3-32.8)$ & $29.8(24.5-36.0)$ \\
\hline$>60$ & 139 & 214228 & 3150 & $64.9(54.8-76.4)$ & $44.1(37.2-51.9)$ \\
\hline
\end{tabular}

$\mathrm{Gl}$, gastrointestinal; $95 \% \mathrm{Cl}, 95 \%$ confidence interval.

${ }^{*}$ Non-overlapping confidence intervals indicate $p<0.05$. 
were considered incident cases of AC if the date of diagnosis fell after the patient was included in the study cohort.

\section{Statistical analyses}

The incidence of $\mathrm{BO}$ and $\mathrm{AC}$ was calculated by dividing the total number of incident cases of $\mathrm{BO}$ or $\mathrm{AC}$ by the total number of person years at risk accumulated by the study population. The incidence of $\mathrm{BO}$ in relation to the number of upper gastrointestinal endoscopies performed was calculated by dividing the total number of incident cases of $\mathrm{BO}$ by the total number of upper gastrointestinal endoscopies performed in the study population.

Incidence rates were calculated by sex and age category; 95\% confidence intervals (95\% CI) were calculated based on a normal distribution. In order to examine the trends over time, we excluded the first (1996) and last (2003) year of the study period because of relatively incomplete follow up. Linear regression analyses were used to estimate time trends.

A three year moving average was calculated to graph the age and sex specific incidence rates over calendar time. In this calculation, the point estimate for one year is the average of the previous year, the present year, and the following year.

R squared values $\left(r^{2}\right)$ were fitted using the method of least squares to identify time trends and to measure the appropriateness of fitting to a linear model. A value of 1 indicates a perfect linear fit.

Differences between groups were tested using the Student's $t$ test in the case of continuous variables after checking for normal distribution, and by the $\chi^{2}$ test in the case of categorical variables.

The 10 year risk of developing $\mathrm{BO}$ was calculated from age specific BO incidence rates that were adjusted for survival probability. Mortality data (2000) from which we calculated survival probability ${ }^{17}$ were obtained from the Dutch Central Bureau of Statistics. ${ }^{18} 19$

\section{RESULTS}

The total study cohort comprised 386002 patients who contributed a total of 1316232 person years of follow up during the study period (mean 3.4 years per person). Fifty per cent were male and mean age at the start of follow up was 35.5 (21.9) years.

The broad computerised search algorithm identified 2542 patients, 491 of whom were classified as definite $(40 \%)$ or possible $(60 \%)$ BO cases after manual review of their medical records. The proportion of possible cases was constant over the calendar years. Two hundred and seventy seven of these cases (56\%) were incident. After requesting additional information, 138 incident cases with histological confirmation and 122 incident cases without histological confirmation available were included in the analyses.

There were more male $(61 \%)$ than female BO patients $(\mathrm{p}<0.01)$. Mean age at diagnosis was lower in men than in women $(59.3$ (13.8) $v 65.5$ (15.0) years; $\mathrm{p}<0.01)$. The overall

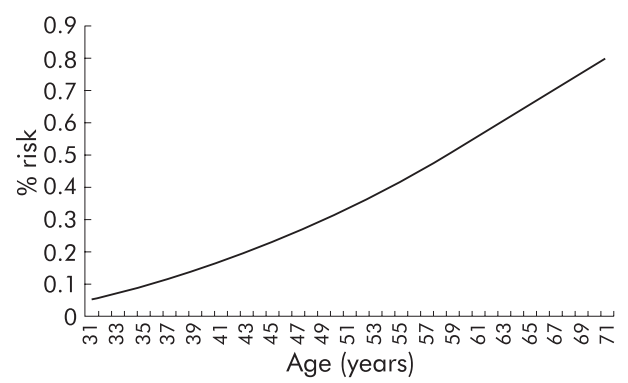

Figure 1 Age related risk for a person to be diagnosed with Barrett's oesophagus over the coming 10 years.

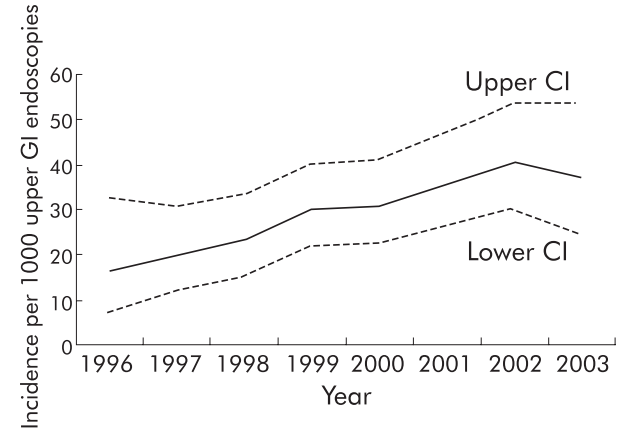

Figure 2 Incidence of Barrett's oesophagus per 1000 upper gastrointestinal endoscopies over calendar time, with upper and lower confidence intervals $(\mathrm{Cl})$.

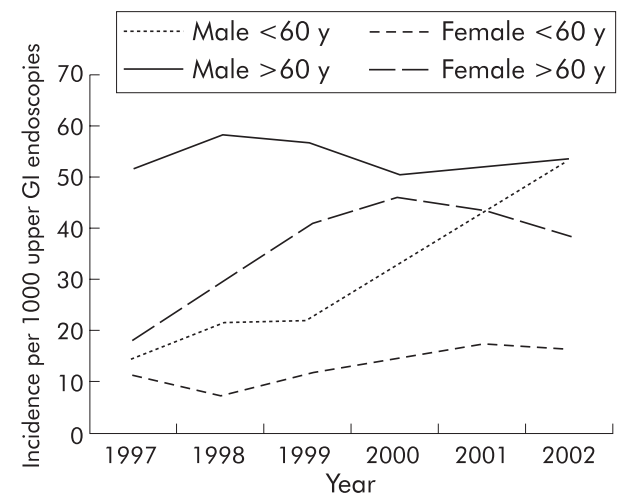

Figure 3 Age and sex specific incidence of Barrett's oesophagus per 1000 upper gastrointestinal endoscopies over calendar time. Points represent three year moving ranges.

incidence of diagnosed BO was 19.8/100 000 person years (95\% CI 17.5-22.3) and was significantly higher in men than in women (table 1 ).

The incidence of BO increased with age $\left(r^{2}=0.98\right.$; table 1) and over calendar time from $14.3 / 100000$ person years in 1997 (95\% CI 8.6-22.4) to 23.1 (95\% CI 17.2-30.6) in 2002 $\left(r^{2}=0.87\right)$. The linear trend over time was significant $(\mathrm{p}<0.05)$. Restricting the analyses to histologically confirmed cases only, the incidence increased from 6.7/100 000 person years (95\% CI 3.2-12.7) in 1997 to 12.6 (95\% CI 8.3-18.3) in $2002\left(r^{2}=0.78\right.$; linear trend $\left.\mathrm{p}<0.05\right)$.

Figure 1 shows the 10 year risk of being diagnosed with BO for symptom free persons at a certain age. For a person of 50 years, the risk of being diagnosed with $\mathrm{BO}$ over the next 10 years, when alive, was $0.3 \%$.

Our computerised search for upper gastrointestinal endoscopies identified 13965 patients with at least one possible upper gastrointestinal endoscopy during the study period. After the electronic validation algorithm and manual review, a total of 10435 upper gastrointestinal endoscopies were identified in 7654 patients over the eight year period. After exclusion of 491 control or surveillance endoscopies for BO or AC and 1449 upper gastrointestinal endoscopies performed within three months of the previous one, 8495 upper gastrointestinal endoscopies were included for the analyses.

Overall, the number of performed upper gastrointestinal endoscopies was 6.5/1000 person years (95\% CI 6.3-6.6). The number of upper gastrointestinal endoscopies was significantly higher among women than men $(6.9 / 1000$ person years (95\%CI 6.7-7.1) v 6.1/1000 person years (95\% CI 5.9$6.2)$ ) and increased with age from $2.6 / 1000$ person years $(95 \%$ 
CI 2.5-2.7) for those aged $<40$ years to $14.7 / 1000$ person years (95\% CI $14.2-15.2)$ for patients $>60$ years $\left(r^{2}=1.00\right)$. Over calendar time the number of upper gastrointestinal endoscopies decreased significantly from 7.2/1000 person years (95\% CI 6.7-7.7) in 1997 to $5.7 / 1000$ person years $(95 \%$ CI 5.4-6.1) in $2002\left(r^{2}=0.52\right.$; linear trend $\left.\mathrm{p}<0.05\right)$.

As shown in fig 2, the incidence of BO per 1000 upper gastrointestinal endoscopies increased linearly from 19.8 (95\% CI 12.0-31.0) in 1997 to 40.5 (95\% CI 30.0-53.5) in $2002\left(r^{2}=0.93\right.$; linear trend $\left.\mathrm{p}<0.05\right)$. Restricting the analyses to histologically confirmed cases only, the incidence increased from 9.3/1000 upper gastrointestinal endoscopies (95\% CI 4.4-17.6) in 1997 to 22.0 (95\% CI 14.6-32.0) in 2002 $\left(r^{2}=0.85\right.$; linear trend $\left.\mathrm{p}<0.05\right)$.

The increase in incidence per 1000 upper gastrointestinal endoscopies was most pronounced for men $<60$ years of age, rising from 21.3 (95\% CI 8.8-43.9) in 1997 to 63.1 (95\% CI $40.2-94.6)$ in $2002\left(r^{2}=0.85\right.$; linear trend $\left.\mathrm{p}<0.05\right)$. The incidence of $\mathrm{BO}$ per 1000 upper gastrointestinal endoscopies for women $>60$ years of age was also noted to be rising, from 24.0 (95\% CI 8.0-56.9) in 1997 to 35.2 (95\% CI 16.6-66.5) in 2002, but this was less consistent with a linear line $\left(r^{2}=0.47\right.$; linear trend $p=0.06$ ) and only based on small numbers. Figure 3 shows the three year moving average age and sex specific incidence rates of $\mathrm{BO}$ over calendar time.

We identified 51 patients diagnosed with AC between 1996 and 2003, 39 (76\%) of whom were male. Mean age at diagnosis was lower in men than in women (66.3 (10.2) $v$ 72.3 (5.4); $\mathrm{p}<0.05)$. The overall incidence was 3.9/100 000 person years (95\% CI 2.9-5.1). The incidence increased over calendar time from $1.7 / 100000$ person years (95\% CI $0.3-5.4$ ) in 1997 to $6.0\left(95 \%\right.$ CI 3.3-10.2) in $2002\left(r^{2}=0.87\right.$; linear trend $\mathrm{p}<0.05$ ).

Seven of the incident AC cases (14\%) had a diagnosis of BO more than one year before the diagnosis of AC. Seven other $\mathrm{AC}$ patients (14\%) were diagnosed with $\mathrm{BO}$ at the time that they were diagnosed with AC (between three months before and three months after the date of diagnosis of AC). The remaining cases had no evidence of $\mathrm{BO}$ recorded before or at the date of diagnosis of AC.

\section{DISCUSSION}

In this study, we observed a linear increase in the incidence of diagnosed BO in the general population, from 14.3/100 000 person years in 1997 to $23.1 / 100000$ person years in 2002 . If the incidence was based on the number of upper gastrointestinal endoscopies performed in the same period, the increase was even more pronounced, from 19.8/1000 upper gastrointestinal endoscopies in 1997 to 40.5/1000 upper gastrointestinal endoscopies in 2002 (fig 2). The incidence of AC increased in the same period, from 1.7/100 000 to 6.0/ 100000 person years.

To our knowledge, only two reports have studied time trends for the incidence of $\mathrm{BO}$ at the population level. The conclusions of these studies were conflicting. Prach and colleagues $^{13}$ showed an increase in incidence from 1.4 new cases of BO per 1000 upper gastrointestinal endoscopies in 1980-1981 to 42.7 new cases of BO per 1000 upper gastrointestinal endoscopies in 1992-1993 in Scotland. They believed their results reflected a true rise in incidence of BO. Conio and colleagues ${ }^{14}$ also observed a strong increase in the incidence of BO per 100000 person years in Minnesota but a similar increase in the number of upper gastrointestinal endoscopies was noted over the same time period. They concluded that the increase in incidence of $\mathrm{BO}$ in their study reflected a rise in upper gastrointestinal endoscopies performed instead of a true increase in $\mathrm{BO}$.

The main risk factor for $\mathrm{BO}$ is gastro-oesophageal reflux disease. The frequency, severity, and duration of acid reflux are positively associated with $\mathrm{BO} .^{2021}$ It has been estimated that approximately $20 \%$ of the general population experience reflux symptoms on at least a weekly basis ${ }^{22}$ and the incidence of reflux oesophagitis is increasing over time. ${ }^{23}$ It has been suggested that the incidence of gastro-oesophageal reflux disease is linked with an increasing average body weight, ${ }^{24}$ and with an increasing average body height in association with a decreasing prevalence of Helicobacter pylori infection in the population. ${ }^{25}$

The rise in incidence of $\mathrm{BO}$ that we observed was most pronounced in men less than 60 years of age (fig 3). A possible explanation could be that men are now exposed to risk factors for $\mathrm{BO}$ at a younger age than they were in the past. Obesity could play a role in this regard. However, obesity at a younger age is also increasing among women, thereby leaving room for other unidentified risk or protective factors for $\mathrm{BO}$.

The observed decline in the number of upper gastrointestinal endoscopies performed per capita in our study is likely to be explained by the introduction of the first general practitioner guidelines on dyspepsia in the Netherlands in 1993, with a revision in 1996. ${ }^{26}{ }^{27}$ These guidelines advised restrictions in referrals for upper gastrointestinal endoscopy in the case of dyspepsia in the absence of alarm symptoms.

Incidence studies conducted with computerised medical records have a risk of misclassification. To limit underestimation we used broad search criteria in free text and manually validated all retrieved records. However, pathological reports on the presence of intestinal metaplasia in the BO segment were not available for all BO patients, even after requesting additional information from general practitioners. Restricting our analyses to only histologically confirmed cases did not however change the observed increasing trend over time.

The reliability of our observed number of upper gastrointestinal endoscopies performed is supported by the similar results of a previous nationwide survey by the Dutch Gastroenterology Association, which reported a total of 130000 upper gastrointestinal endoscopies performed in 2000 in the Netherlands, equalling approximately 8.1/1000 person years. ${ }^{28}$ As we excluded control and surveillance endoscopies for $\mathrm{BO}$ or $\mathrm{AC}$, and also upper gastrointestinal endoscopies performed within three months of the previous one, we feel that our results truly reflect clinical practice in the area under study.

We repeated our analyses including all upper gastrointestinal endoscopies performed within three months of the previous one to assess if this modification changed our results. The incidence of BO per 1000 upper gastrointestinal endoscopies was somewhat lower than in our original analyses but both lines were parallel, indicating a similar increase in incidence of BO over time (data not shown).

It is well known that not all BO patients have reflux symptoms. ${ }^{29-31}$ As a consequence, most of these patients will not undergo upper gastrointestinal endoscopy and cases will be missed. A study by Cameron and colleagues ${ }^{32}$ showed a 21 -fold higher number of cases of BO based on autopsy findings than was actually seen in the population. This clearly illustrates the magnitude of the potential underestimation of $\mathrm{BO}$ in the general population. We assume that such under detection of BO was present in our study also, implying that the actual incidence rate of $\mathrm{BO}$ could be considerably higher than that found in our study. However, there is no reason to believe that the degree of this underestimation has changed over time.

The increased incidence of BO over time may partly have resulted from an increased awareness and the improved skills of endoscopists in diagnosing the presence of Barrett's mucosa. If this is the case, then the observed increase in 
incidence of BO would, at least in part, be due to a higher detection rate of Barrett's patients, instead of a real rise in incidence. The distinction between long and short segment Barrett's might provide further insight as the observer variability is expected to be lower in long segment BO. Unfortunately, such a distinction is not possible in our database. However, the differing trend in incidence between age groups (fig 3 ) does not support the explanation that the increasing incidence is only secondary to an increased awareness or a change in diagnostic criteria. If increased awareness is solely responsible for the increase in incidence we observed, we would expect similar time trends in the different age groups, and for males and females.

It is likely that the number of patients with AC reported here is underestimated as we excluded patients with oesophageal cancer of unknown type $(n=23)$. Including these patients did not change the trend over time (data not shown). As differentiation between oesophageal cancer and cancer of the gastric cardia, which we did not include, is difficult, it is possible that some additional cases were missed.

Estimates for the incidence of AC were based on small numbers and had wide confidence intervals. Despite the fact that chance may explain at least some of our results, another study in the Netherlands, based on the Dutch Cancer Registry, showed an increase of similar magnitude in the incidence of AC over a six year period preceding our study (1990-1996). ${ }^{33}$

It seems that the increase in incidence of AC between 1997 and 2002 was greater than the increase in incidence of BO over the same period. As it is generally expected that progression from BO to AC takes several years, it may be that the incidence trend for $\mathrm{AC}$ in this study reflects the incidence trend for $\mathrm{BO}$ from several years ago and the increase in incidence of $\mathrm{BO}$ is slowing down at present. It is also possible that the rising incidence of $\mathrm{BO}$ is not solely responsible for the increase in incidence of AC. Other factors may also be important such as those influencing the rate of malignant progression from BO to AC.

In conclusion, our results showed an increase in the incidence of detected $\mathrm{BO}$, which cannot be explained by a rise in the number of upper gastrointestinal endoscopies performed. The cause of this increase and its implications require further study but it is likely that a further increase in the incidence of $\mathrm{BO}$ carcinomas in the coming decade will occur.

\section{Authors' affiliations}

E M van Soest, Department of Gastroenterology and Hepatology, and Department of Medical Informatics, Erasmus University Medical Centre, Rotterdam, the Netherlands

P D Siersema, E J Kuipers, Department of Gastroenterology and Hepatology, Erasmus University Medical Centre, Rotterdam, the Netherlands

J P Dieleman, Department of Medical Informatics, Erasmus University Medical Centre, Rotterdam, the Netherlands

M C J M Sturkenboom, Department of Epidemiology and Biostatistics, and Department of Medical Informatics, Erasmus University Medical Centre, Rotterdam, the Netherlands

Conflict of interest: None declared.

\section{REFERENCES}

1 Pera M, Cameron AJ, Trastek VF, et al. Increasing incidence of adenocarcinoma of the esophagus and esophagogastric junction. Gastroenterology 1993;104:510-13.
2 Blot WJ, Devesa SS, Fraumeni JF Jr. Continuing climb in rates of esophageal adenocarcinoma: an update. JAMA 1993;270:1320.

3 Bytzer P, Christensen PB, Damkier P, et al. Adenocarcinoma of the esophagus and Barrett's esophagus: a population-based study. Am J Gastroenterol 1999.94:86-91.

4 Blot WJ, Devesa SS, Kneller RW, et al. Rising incidence of adenocarcinoma of the esophagus and gastric cardia. JAMA 1991;265:1287-9.

5 Devesa SS, Blot WJ, Fraumeni JF Jr. Changing patterns in the incidence of esophageal and gastric carcinoma in the United States. Cancer 1998:83:2049-53.

6 Wu AH, Wan P, Bernstein L. A multiethnic population-based study of smoking, alcohol and body size and risk of adenocarcinomas of the stomach and esophagus (United States). Cancer Causes Control 2001;12:721-32.

7 Chow WH, Blot WJ, Vaughan TL, et al. Body mass index and risk of adenocarcinomas of the esophagus and gastric cardia. J Natl Cancer Inst 1998;90:150-5.

8 Clark GW. Effect of Helicobacter pylori infection in Barrett's esophagus and the genesis of esophageal adenocarcinoma. World J Surg 2003;27:994-8.

9 Sampliner RE. Updated guidelines for the diagnosis, surveillance, and therapy of Barrett's esophagus. Am J Gastroenterol 2002;97:1888-95.

10 Solaymani-Dodaran M, Logan RF, West J, et al. Risk of oesophageal cancer in Barrett's oesophagus and gastro-oesophageal reflux. Gut 2004;53:1070-4.

11 Hage M, Siersema PD, van Dekken $\mathrm{H}$, et al. Oesophageal cancer incidence and mortality in patients with long-segment Barrett's oesophagus after a mean follow-up of 12.7 years. Scand J Gastroenterol 2004;39:1175-9.

12 Haggitt RC, Tryzelaar J, Ellis FH, et al. Adenocarcinoma complicating columnar epithelium-lined (Barrett's) esophagus. Am J Clin Pathol 1978;70: 1-5.

13 Prach AT, MacDonald TA, Hopwood DA, et al. Increasing incidence of Barrett's oesophagus: education, enthusiasm, or epidemiology? Lancet 1997:350:933.

14 Conio M, Cameron AJ, Romero Y, et al. Secular trends in the epidemiology and outcome of Barrett's oesophagus in Olmsted County, Minnesota. Gut $2001 ; 48: 304-9$

15 Lamberts H, Wood M, Hofmans-Okkes IM. International primary care classifications: the effect of fifteen years of evolution. Fam Pract 1992;9:330-9

16 Vlug AE, van der Lei J, Mosseveld BM, et al. Postmarketing surveillance based on electronic patient records: the IPCI project. Methods Inf Med 1999;38:339-44.

17 Rothman KJ, Greenland S. Measures of disease frequency. In: Rothman KJ, Greenland S, eds. Modern epidemiology. Philadelphia: Lippincott-Raven Publishers, 1998:29-46.

18 Bevolking per regio naar leeftiid, geslacht en burgerlijke staat. Centraal Bureau voor Statistiek. http://statline.cbs.nl, 2004-10-20.

19 Overledenen naar diverse kenmerken per regio. Centraal Bureau voor Statistiek. http://statline.cbs.nl, 2004-10-20.

20 Lieberman DA, Oehlke M, Helfand M. Risk factors for Barrett's esophagus in community-based practice. GORGE consortium. Gastroenterology Outcomes Research Group in Endoscopy. Am J Gastroenterol 1997;92:1293-7.

21 Campos GM, DeMeester SR, Peters JH, et al. Predictive factors of Barrett esophagus: multivariate analysis of 502 patients with gastroesophageal reflux disease. Arch Surg 2001;136:1267-73.

22 Locke GR III, Talley NJ, Fett SL, et al. Prevalence and clinical spectrum of gastroesophageal reflux: a population-based study in Olmsted County, Minnesota. Gastroenterology 1997; 1 12:1448-56.

23 Loffeld RJ, van der Putten AB. Rising incidence of reflux oesophagitis in patients undergoing upper gastrointestinal endoscopy. Digestion 2003:68:141-4.

24 Murray L, Johnston B, Lane A, et al. Relationship between body mass and gastro-oesophageal reflux symptoms: The Bristol Helicobacter Project. Int J Epidemiol 2003;32:645-50.

25 Axon ATR. Personal view: to treat or not to treat? Helicobacter pylori and gastro-oesophageal reflux disease-an alternative hypothesis. Aliment Pharmacol Ther 2004; 19:253-61.

26 Numans ME, de Wit NJ, Geerdes RHN, et al. NHG-Standaard Maagklachten. Huisarts Wet 1993;36:375-9.

27 Numans ME, de Wit NJ, Geerdes RHN, et al. NHG-Standaard Maagklachten (Eerste herziening). Huisarts Wet 1996;39:565-77.

28 Endoscopie in Nederland. Genootschap van Maag-, Darm-, Lever-artsen. www.mdl.nl/doc/endoscopie.pdf, 2004-09-29.

29 Gerson LB, Shetler K, Triadafilopoulos G. Prevalence of Barrett's esophagus in asymptomatic individuals. Gastroenterology 2002;123:461-7.

30 Cooper GS, Yuan Z, Chak A, et al. Association of prediagnosis endoscopy with stage and survival in adenocarcinoma of the esophagus and gastric cardia. Cancer 2002;95:32-8.

31 Corley DA, Levin TR, Habel LA, et al. Surveillance and survival in Barrett's adenocarcinomas: a population-based study. Gastroenterology 2002; 122:633-40

32 Cameron AJ, Zinsmeister AR, Ballard DJ, et al. Prevalence of columnar-lined (Barrett's) esophagus. Comparison of population-based clinical and autopsy findings. Gastroenterology 1990;99:918-22.

33 Wijnhoven BPL, Louwman MWJ, Tilanus HW, et al. Increased incidence of adenocarcinomas at the gastro-oesophageal junction in Dutch males since the 1990s. Eur J Gastroenterol Hepatol 2002;14:115-22. 